\title{
Dosimetry for radiobiology experiments at GANIL
}

\author{
Florent Durantel $^{\mathrm{a}, *}$, Emmanuel Balanzat $^{\mathrm{a}}$, Amine Cassimi ${ }^{\mathrm{a}}$, François Chevalier ${ }^{\mathrm{b}}$, \\ Yvette Ngono-Ravache ${ }^{a}$, Toiammou Madi ${ }^{a}$, Jean-Christophe Poully ${ }^{a}$, Jean-Marc Ramillon ${ }^{a}$, \\ Hermann Rothard ${ }^{a}$, Frédéric Ropars ${ }^{a}$, Lucas Schwob ${ }^{a}$, Isabelle Testard ${ }^{c}$, \\ Yannick Saintigny ${ }^{\mathrm{b}}$ \\ a CIMAP-GANIL, Caen, France \\ ${ }^{\mathrm{b}}$ CEA/DSV/LARIA, Caen, France \\ ${ }^{\text {c } C E A / D S V / C B M / i R T S V, ~ G r e n o b l e, ~ F r a n c e ~}$
}

\section{A R T I C L E I N F O}

\section{Article history:}

Received 30 October 2015

Received in revised form

14 January 2016

Accepted 18 January 2016

Available online 9 February 2016

Keywords:

High energy heavy ions

Carbon hadrontherapy

$\mathrm{X}$-ray detector

CR39

\begin{abstract}
A B S T R A C T
Mainly encouraged by the increasing application of ion beams for cancer treatment (hadron-therapy) including carbon beams, the use of heavy ion facilities for radiobiology is expanding rapidly today. As an alternative to dedicated centers for treatment and medical research, accelerators like GANIL offer the possibility to undertake such experiments.

Since 20 years, CIMAP, reinforced 15 years ago by the biological host laboratory LARIA, has been receiving researchers in radiobiology and assisted them in performing experiments in different fields such as hadron-therapy, space radioprotection and fundamental biological and physico-chemical mechanisms. We present here a short description of the beam line and the on-line equipments that allow the automatic irradiation of up to 24 biological samples at once.

We also developed an original on-line beam monitoring procedure for low ion flux (low dose rates) based on the measurement of the K-shell X-rays emitted from a thin iron foil. This detector is calibrated on an absolute scale before each experiment by counting etched tracks on an irradiated CR39 polymer plate. We present the performances and limits of this method and finally give typical fluence (dose) uncertainties for a standard irradiation in radiobiology.
\end{abstract}

(c) 2016 Elsevier B.V. All rights reserved.

\section{Introduction}

The spectacular development of radiobiology during the last decades is largely due to advances in hadron-therapy and therapeutic hopes it raises in the treatment of cancers. Hadron-therapy is indeed an innovative technique based on the use of heavy ion beams or protons for tumor treatment in either replacement of or addition to widely practiced X-rays treatments.

Unlike X-rays, the energy deposition of the hadrons can reach a maximum and be very well localized in-depth. This ballistic exploitation and the resulting accuracy of the well known Bragg curve gives strength to this method, as it seems more appropriate to treat internal localized tumors in the vicinity to radiationsensitive organs which would be considerably affected by the radiation field of less localized energy deposition by X-rays [1].

Although the idea of using proton beams for radiotherapy has been suggested very early in the 1940s by Robert Wilson [2], the first real clinical treatment centers (exclusively for clinical applications)

\footnotetext{
* Corresponding author.

E-mail address: durantel@ganil.fr (F. Durantel).
}

were born in 1990 (LLUMC, Loma Linda University Medical Center). Their number is now increasing rapidly and expected to exceed 50 in 2015 [3] with a result of 110,000 patients treated worldwide ( $85 \%$ in protons).

Heavy ions present both higher dose deposition capacities and better ballistic properties and in particular, carbon ions appear to have some significant clinical benefits [4]. Until a few years ago, carbon treatment centers were not numerous and mostly localized in two countries (HIMAC, HIBTM, NIRS in Japan and GSI in Germany).

But with the advent of new generations of low cost turnkey accelerators, dedicated to industrial use, treatment center projects are multiplying (CNAO, HIT, MEDAUSTRON, ARCHADE, only to mention Europe) [5]. Pending the construction of these new centers, the demands of beam time for research purposes are increasingly important, which mainly explains the use of structures originally designed for other applications. Thus, at GANIL (Grand Accélérateur National d'Ions Lourds, Caen, France) a quota of beam time is intended for interdisciplinary (i.e. non nuclear) research, including radiobiology. The laboratory CIMAP (Centre de recherche sur les Ions, les MAtériaux et la Photonique) undertakes 
the interdisciplinary research at GANIL and manages, through its so called CIRIL $^{1}$ platform and together with the biology laboratory LARIA (Laboratoire d'Accueil et de Recherche avec les Ions Accélérés, CEA), the hosting of experiments in radiobiology [6].

The GANIL accelerator can provide various beams, from carbon to uranium, at maximum energies ranging from $95 \mathrm{MeV} / \mathrm{A}$ for light ions down to $24 \mathrm{MeV} / \mathrm{A}$ for uranium. This diversity allows expanding the activities to space radiation biology studies and the study of fundamental processes. On the other hand, cyclotrons supply only a fixed energy ${ }^{2}$, but which can be reduced afterward by beam degraders.

In Part 2 we describe the beam line and instruments that have been developed for radiobiology experiments. This adaptation of a physics machine to biological context with its specific constraints is reinforced by the presence of LARIA since 2003. Part 3 is dedicated to the monitoring of low beam intensities and the description of dosimetry carried out for each experiment. The proposed method aims to be not only compatible with the specificities of a large nuclear physics facility, but also to guarantee a good repeatability which is of a great interest for experiments sometimes spaced by more than a year. An evaluation of standard uncertainties will be given.

\section{Beam line and equipments}

\subsection{Beam line}

The radiobiology experiments take place in the D1 cave on the so called IRRABAT beam line, which is also the name of the diagnostic and experiment vacuum chamber used in a standard way for high energy irradiations. At the end of the line, after crossing a stainless steel window of $25 \mu \mathrm{m}$ thickness, an automated sample holder of 24 positions is installed. It allows handling and processing in a single irradiation run a set of 4 lines with 6 flasks each, in order to limit the number of time consuming access into the cave. Vertical and horizontal motions are controlled by two step-motors allowing a precise positioning of the samples in front of the beam.

The optics of the line was adapted to focus the beam behind IRRABAT, just on the position of the flasks. The standard characteristics of the beam are the following ones ${ }^{3}$ : a spotlight on the target of $13 \times 13 \mathrm{~mm}^{2}$ size, a deflection angle (semi angle with the medium beam axis) of $10 \mathrm{mrad}$ in horizontal direction and $15 \mathrm{mrad}$ in vertical direction, an emittance of $5 \times 5 \pi \mathrm{mm}$.mrad and a resolution in energy $\Delta W / w$ of 0.007 (see Figs. $1 \mathrm{~A}$ and 2).

With the help of two fast scanning magnets, the beam is swept horizontally at a frequency of $425.8 \mathrm{~Hz}$ and vertically at a frequency of $4.4 \mathrm{~Hz}$. Both frequencies are chosen to avoid that one is a multiple of the other. In this way, no spatial structure (like Lissajous figure) is artificially created, which would damage the homogeneity of the dose deposition. The maximum reachable scanning surface is $60 \times 60 \mathrm{~mm}^{2}$, allowing a maximal irradiation field large enough for a $25 \mathrm{~cm}^{2}$ flask. A couple of horizontal and vertical slits delimit accurately the irradiation field area. This data is used in the calculation of the fluence. Upstream of the line, a thin Ta foil can be inserted into the beam path in order to smooth and homogenize the beam spot, if needed.

At the beginning of each experiment the radiation field defined by both the amplitude of scanning and the position of the slits (Fig. 1B), is visually controlled by irradiating (with a dose of usually around $8 \mathrm{~Gy}$ ) a Gafchromic EBT2 type film, placed on a flask in the sample holder.

${ }^{1}$ CIRIL: Centre Interdisciplinaire de Recherche avec des Ions Lourds; www. cimap.ensicaen.fr.

${ }^{2}$ The tuning of the cyclotrons to a new energy takes time on the experiment. It is generally an option which is not retained by the experimenters.

${ }^{3}$ These values might slightly change from an experiment to another
Until now, these films were only used for checking the size and position of the radiation field, but it might be possible in the future to use them for an additional dosimetry by exploiting the optical density variations of the film. Some teams are working on this topic [7-9].

The precise beam spot position depends on each upstream beam tuning, so the zero beam position has to be adjusted by use of set of horizontal and vertical steerers. This zero position is placed out of the irradiation area (that is "in the slits"), where the scanning amplitude is zero. This allows, on the one hand, setting the reversal point of the sweeping out of the area to be irradiated, so as not to impair the homogeneity of the dose deposition, and, on the other hand, protecting the sample in case of failure of the scanning magnets.

\subsection{Biological side: LARIA facility}

The radiation-biology research laboratory LARIA embedded at GANIL hosts experiments in biology thanks to a partnership with CIMAP. The biology platform operated by LARIA includes a comprehensive tissues culture room, a molecular biology laboratory and a proteomic laboratory allowing hosted teams to perform various canonical assays in the radiation biology field. Furthermore, the platform may be adapted for special requirements if needed. The automatic biological sample holder may be used with 12.5 and $25 \mathrm{~cm}^{2}$ flasks, tubes $(0.5 ; 1.5 ; 2$ and $15 \mathrm{ml})$, lab-tek ${ }^{\mathrm{TM}}$ chamber slide, $8 \mathrm{~cm}^{2}$ culture dishes, 96-well plates (36 wells irradiated).

Fields of interest of platform users are either radiation protection of space travelers (healthy tissues) or cancer treatment (tumors and surrounding healthy tissues). During the late 15 years, multiple ions were used with an emphasis on carbon ions. To date, 20 peer-reviewed articles of radiation biology were published with data obtained at GANIL on the IRRABAT beam line, as summarized in the table of Annex 1.

\section{Dosimetry}

\subsection{Method and main results}

The typical dose rates used during a radiobiology experiment are of the order of few $\mathrm{Gy} / \mathrm{min}$ (equivalent in water), this implies, for a ${ }^{12} \mathrm{C}$ beam of $75 \mathrm{MeV} / \mathrm{A}$, fluxes of about $310^{5}$ ions/( $\left.\mathrm{s} \cdot \mathrm{cm}^{2}\right)$ which, considering the typical radiation fields, corresponds to $\approx 10^{7}$ ions/s. This intensity is far too low to be correctly measured and monitored by the standard methods applied at GANIL for non-biological samples. The latter are based on current measurements for monitoring the beam intensity via Faraday cups, and the secondary electron emission of a thin metallic foil [10]. The alternative method developed in the laboratory is based on the measurement of the emitted K-shell X-rays when the beam passes through a thin metallic foil.

Dosimetry, or calibration of this X-ray detector, is divided into two stages:

1. Calculation of the expected X-ray count rate. This step may be optional, since it does not belong to the calibration process itself, but it saves a considerable amount of time by adjusting immediately the different parameters of the detector to the right range of fluence.

2. Calibration of the whole detector and acquisition chain by an absolute measurement of the fluence by means of a CR39 polymer sheet track-etched detector.

\subsubsection{Set-up}

A thin metallic (Fe) foil (from 5 up to $25 \mu \mathrm{m}$ thick and tilted with respect to the beam axis) is placed inside the IRRABAT chamber (item 'a' on Fig. 3). A $25 \mu \mathrm{m}$ thick stainless steel exit window (item 'b' on Fig. 3) $15 \mathrm{~cm}$ downstream, separates the high vacuum in the beam line 
A

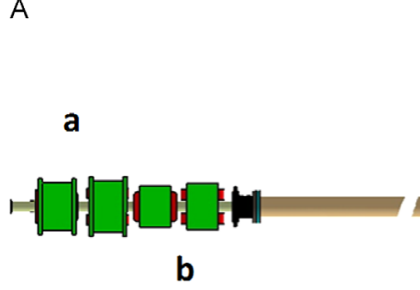

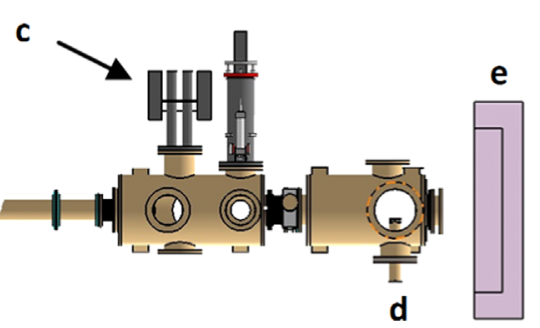

B

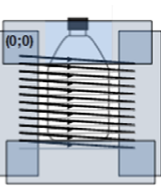

Fig. 1. (A) D1 Beam line and IRRABAT - (a) fast scanning magnets; (b) steerers; (c) $H$ and $V$ slits; (d) X-ray detector; (e) sample holder position. (B) Zero position of the beam with respect to the slits position during the beam scanning.

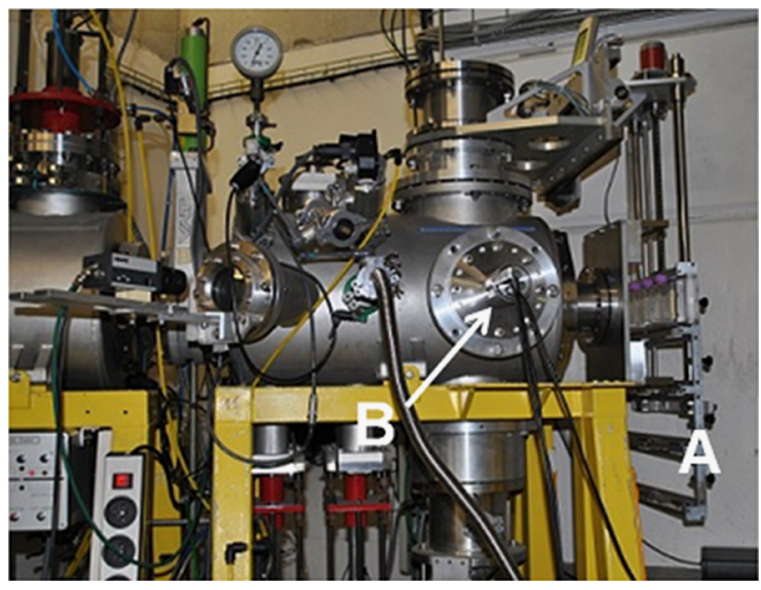

Fig. 2. IRRABAT: (A) Sample Holder 24 positions. (B) PM detector and preamplifier.

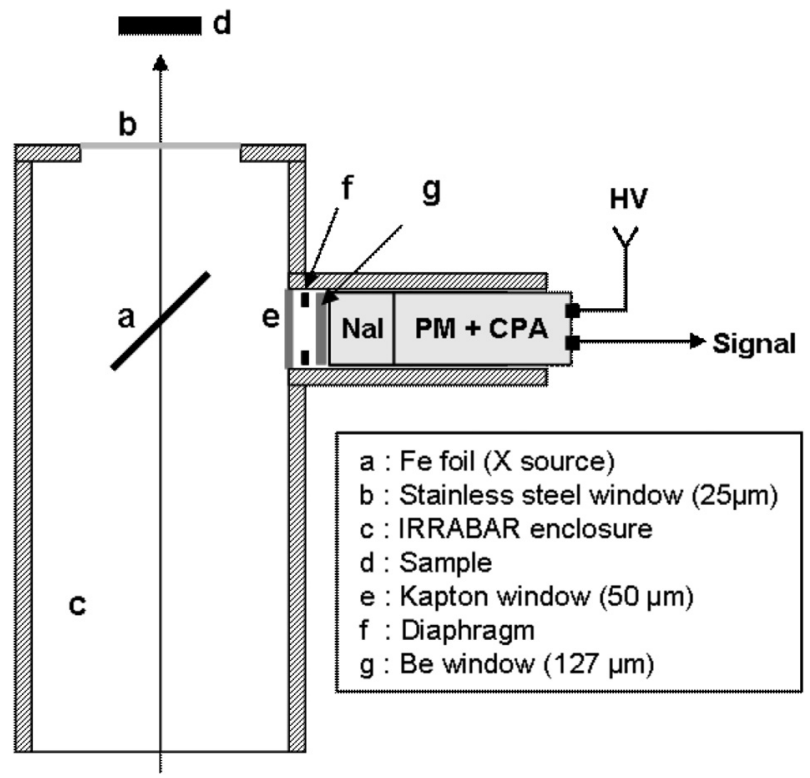

Fig. 3. IRRABAT chamber and $X$ detector.

from the ambient atmosphere in which the irradiated samples are placed. The K-shell ionization of the target atoms by the ion beam creates X-ray photons. The configuration is optimized to collect the K $\alpha$ photons. The photon energy spectrum is measured with a scintillator and Photo Multiplier (PM) set, placed $90^{\circ}$ to the beam axis. The position of the detector can be varied and a diaphragm of variable diameter is placed in front of the scintillator window: in this way, the solid angle of X-ray detection can be adjusted. The scintillator is a classic NaI (Tl) crystal, $1 \mathrm{~mm}$ thick. Although developed in the 1940s [11], this type of inorganic scintillators is still widely used nowadays. $\mathrm{NaI}(\mathrm{Tl})$ scintillators offer a good compromise between a high light yield ( about $4 \cdot 10^{4}$ photons/MeV) and a decay time of 230 ns compatible with count rates for standard ion beam intensities used in

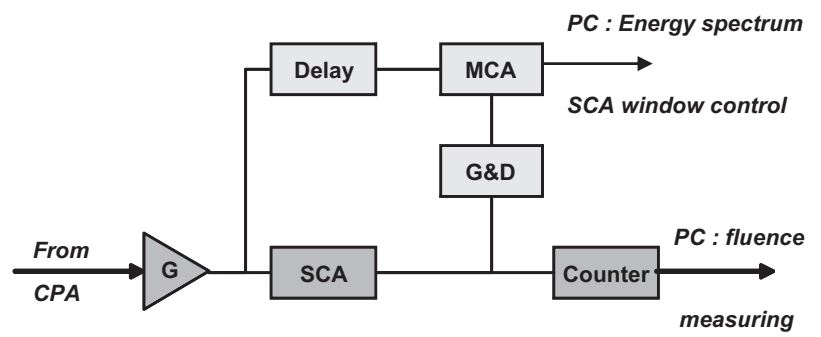

Fig. 4. $\mathrm{X}$ detector signal processing. The coincidence circuit allows adjusting the SCA window in order to limit the noise of X-ray signal.

radiobiology. The low energy resolution (6.5\% at $660 \mathrm{keV} \mathrm{[12])} \mathrm{does}$ not present a major drawback in simple counting operations. A charge preamplifier is placed close to the detector behind the PM. The signal is then transferred to the control/acquisition room.

\subsubsection{Acquisition chain}

From the charge preamplifier, the signal is injected into a shaper amplifier and then "windowed" by a Single Channel Analyzer (SCA) (Fig. 4). The upper and lower levels of the SCA are controlled by displaying the energy spectrum of the signal by means of a Multiple Channel Analyzer (MCA). This level adjustment allows suppressing the electronic noise on the one hand and the tail-end of energy distribution that may not correspond to the expected K-lines, on the other.

The counting noise can be estimated straight after irradiation in the range of $5-10$ counts/s - for a standard irradiation at $6 \cdot 10^{5}$ ions/ $\left(\mathrm{s} \cdot \mathrm{cm}^{2}\right)$. These values take into account both the electronic noise of the acquisition and the activation of the line, whose radioactive decay is fast. The upper limit of the counting rate is limited to about 6000 counts/s, since beyond this level, some signal pile-up starts to be observed. Therefore, the best working conditions are usually found close to about 3000 counts/s.

The irradiation procedure is fully conducted via dedicated computer software. Input parameters, provided by the user are the beam parameters, the irradiated surface and the set point fluence $\Phi$ :

$\Phi=k \cdot \frac{N_{x} C_{x}}{S_{i r r}}$

where $k$ is the inverse of the ion charge (in $C^{-1}$ ), $N_{x}$ is the X-ray counting, $C_{x}$ is the calibration constant $(C / X)$ and $S_{i r r}$ the irradiation surface (in $\mathrm{cm}^{2}$ ) calculated knowing the position of the slits.

Flux monitoring is done by measuring the fluence change, $\Delta \Phi$, at fixed time intervals, $\Delta t$ :

$\varphi=\Delta \Phi / \Delta t$

It should be noticed that the measurement chain is calibrated in fluence. From the biological side, according to the recommendations of the SI, the clinical requirements and established practices, dose results should be reported in Gray [13]. The dose deposited on a given layer of material of density $\rho$ can be calculated from the fluence as follows:

$D[\mathrm{~Gy}]=1.610^{-9} \times \frac{d E}{d x} \times[\mathrm{keV} / \mu \mathrm{m}] \times \Phi\left[\mathrm{cm}^{-2}\right] \times \frac{1}{\rho}\left[\mathrm{cm}^{3} / \mathrm{g}\right]$ 
where $d E / d x$ is the mean linear energy loss of the ion in the layer and can be assimilated to the linear energy transfer LET, which is the energy received by the material [14]. The passage from "dose" to "fluence" requires knowing the LET. The information provided by the accelerator to the users is the ion beam energy at the entrance of the biological system. With this information and depending on the nature of their samples, users can calculate the appropriate LET. Without further information on the studied biological system, a LET value based on a water model and extracted from a SRIM calculation [15] is provided for information purpose. However, this value is not required for the calibration procedure. As an example, Annex 1 illustrates the target fluence to be reached for a desired dose, with liquid water hypothesis $\left(\rho=1 \mathrm{~g} / \mathrm{cm}^{3}\right)$.

\subsubsection{CR39 Calibration}

CR39, Polyallyl diglycol carbonate, $\mathrm{C}_{12} \mathrm{H}_{18} \mathrm{O}_{7}$, is a rigid polymer with excellent surface qualities, even after etching, and is widely used as a track detector [16-18]. Above a threshold in LET, around $5 \mathrm{keV} /$ microns [19-21], a charged particle that passes through the sheet forms a latent track in the polymer. The individual counting of each track becomes possible after a controlled chemical etching process that progressively enlarges the tracks from nanometers up to micrometers. In the present case, we use a $12 \mathrm{~N} \mathrm{KOH}$ solution in which the material is immersed for about $12 \mathrm{~min}$ at $80^{\circ} \mathrm{C}$. These very severe conditions, compared to the ones generally used for track etching in polymers, are the result of a compromise concerning the devoted time: the need of obtaining a good track quality for an optimal counting versus minimizing time for dosimetry. This fast etching is acceptable as long as no further analysis such as influence of LET or fine particle discrimination is carried out.

The X-ray chain is calibrated for each new experiment, or every time the X-ray production yield may change (different projectile and/or energy). For each calibration, three CR39 films are irradiated at target fluences $\Phi_{t}$ of $10^{6}, 2 \cdot 10^{6}$, and $3 \cdot 10^{6}$ ions $/ \mathrm{cm}^{2}$. These target fluences are measured by the X-ray chain using a theoretical calibration constant, $C_{x t h e o}$, calculated as explained below. The comparison between the target fluences and the corresponding fluences $\Phi_{C R 39}$ measured on the CR39 plates allows correcting the calibration constant by a factor $f_{c} . f_{c}=\Phi_{C R 39} / \Phi_{t}$ with $\Phi_{C R 39}=N_{C R 39} / S_{\text {micro }}$ and $\Phi_{t}=k C_{x t h e o} N_{x} / S_{\text {irr }}$ hence, the calibrated fluence can be expressed as:

$\Phi=\frac{k C_{x t h e o}}{S_{\text {irr }} \phi_{t}} N_{x} \Phi_{C R 39}$

The track counting is performed with a $1000 \times$ magnification optical microscope $(10 \times$ camera focus and $\times 100$ oil immersed objective), in a precisely calibrated field, thereby allowing direct determination of fluence. The choice of these fluences also results in a compromise: With a $1000 \times$ magnification the appropriate size of tracks is $\approx 2 \mu \mathrm{m}$; below $10^{6}$ ions $/ \mathrm{cm}^{2}$ the tracks are too rare and thus the statistical uncertainties are high. At the opposite, above $310^{6}$ ions $/ \mathrm{cm}^{2}$, the track overlapping begins to be noticeable and affects the accuracy of the counting.

The main drawback of our approach (X-ray monitoring and CR39 calibration) is a relatively limited dynamics in terms of dose rate. For ensuring an acceptable homogeneity of the field, the minimum exposure time is $\approx 30 \mathrm{~s}$ which corresponds to a couple of hundred vertical passages of the beam on the frame. The maximum flux for the CR39 calibration is then $110^{5} \mathrm{~cm}^{-2} \mathrm{~s}^{-1}$ (3 $10^{6} \mathrm{~cm}^{-2}$ in $30 \mathrm{~s}$ ), hence for $\mathrm{C}$ beams at $75 \mathrm{MeV} / \mathrm{A}$, the maximum dose rate useful for calibration is $\approx 0.2 \mathrm{~Gy} \mathrm{~min}^{-1}$.

During an experiment, because of the limited counting dynamics of the X-ray chain ( $50<N_{x}<6000$ counts/s), the ratio between maximum and minimum dose rate achievable is in the same proportion i.e. $\varphi_{\max } / \varphi_{\min } \approx 120$. The solid angle for the X-ray detection is tuned for each calibration in order to adapt the counting rate at the expected mean dose rate. Thus, taking the higher calibration points as the lower limit of the dose rate range leads to an upper limit of $\approx 10 \mathrm{~Gy} \mathrm{~min}^{-1}$. Obviously, the higher the LET, the higher the maximum dose rate. Applying our approach to higher dose rates, would imply increasing the calibration range by increasing the fluence on the CR39 plates and hence observing much smaller tracks. This would require different analyzing capacities much more powerful than a simple optical microscope (AFM type for instance), which are hardly compatible with quick routine calibration procedures, as needed here [22].

The pros of this method are: simplicity, relatively low cost and possibility of performing an absolute dosimetry by means of both an exhaustive counting and a selective one:

- The track geometry (with completely different angles, for instance) allows to exclude the particles not linked to the beam [23].

- Under $100 \mathrm{MeV} / \mathrm{A}$ for a carbon beam, and considering the thin layer of crossed material $(1.5 \mathrm{~mm})$ we assume the fragmentation of the projectile to be negligible. This is probably not the case with a degraded beam and it would be interesting to probe to what extend this discrimination is possible in these conditions [24-26].

- In any case, a SRIM calculation shows that light particles like protons or $\alpha$ particles should not be recorded in CR-39 as their stopping power $(\approx 1 \mathrm{keV} / \mu \mathrm{m}$ ) is lower than the polycarbonate threshold.

\subsubsection{Results and measurement uncertainties}

The calibration method described above allows to eliminate numerous systematic errors which could be caused by the electronic gain of the chain, solid angles, irradiation surface and theoretical constant $C_{x}$. The precision of this correction depends on the fluence measurement accuracy with the CR39. The first important remaining error therefore stems from the estimation of the surface of the CR39 picture provided by the microscope, since the direct calculation of fluence by track counting strongly depends on this parameter. A precise measurement of this observation field reduces this error down to $1 \%$ per dimension.

The second, and principal, source of error can be attributed to the statistical uncertainty on track counts. The corresponding counting value for each fluence to be calibrated is the average of the number of counts on a statistical sample of 10 pictures randomly distributed over the entire CR39 film. This number of ten pictures has been arbitrary chosen in order to reduce the standard deviation on the mean counting values and minimize the duration of the calibration step. Considering a posteriori a very large collection of pictures sample, we can estimate a confidence interval at 2, 4 or 6 sigmas of the average of the counting of 10 images, as illustrated in Table 1 . The results of about $5 \%$ for 2-sigma uncertainties do not reach the precision of primary standards like calorimeters (which are complicated to implement), but they are consistent and compatible with the results published in recent years for fluence based methods and standards for flat ionization chambers designed for scanned heavy ion beams [27,28].

Another irradiation of CR39 performed at the end of experiments for control purposes does not show a deviation larger than $3 \%$ from the initial calibration. It thus allows saying that no significant drift of the X-ray acquisition chain is observed during the run.

Regarding random uncertainties, Eq. (4) shows in turn that the uncertainties in the measurement of fluence depend on the X-ray counting $N_{x}$. The noise on the counting rate as mentioned before is at most $10 \mathrm{cts} / \mathrm{s}$, leading to a ratio of $0.5 \%$ for a standard functioning of the acquisition chain around $2000-3000 \mathrm{cps} / \mathrm{s}$. It can be noted, however, that part of this mean value of the counting noise is already taken into account in the CR 39 calibration at low flux. 


\subsection{Further details in description and analysis}

\subsubsection{Estimation of $X$-count-rate}

The theoretical constant $C_{x t h e o}$ depends on the solid angle of detection $\Omega$ and the number of X-rays created per incident ion, $n_{x i}$ :

$C_{x t h e o}=\frac{k}{n_{x i} \Omega}$

For simplifying the estimation of $C_{x t h e o}$, the solid angle is crudely estimated assuming a equivalent $\mathrm{X}$-ray source in the center of the radiation field. Thus, the number of X-rays created during the passage of an ion through a metallic sheet of thickness $d$ tilted at the angle $\theta=\frac{\pi}{2}-\varphi$ from the beam axis is given by:

$n_{x i}=\sigma \cdot N \cdot \tan \varphi[1-\exp (-\mu d \tan \varphi)] \cdot T \cdot T_{B e}$

with:

$\sigma=\sigma_{i} \cdot Y_{\text {fluo }}\left(K_{\alpha}\right)$

being the product of the K-shell ionization cross section, $\sigma_{\mathrm{i}}$, and the fluorescence yield $Y_{\text {fluo }}$ for the $K_{\alpha}$ lines [29]. $T$ and $T_{B e}$ are the transmission coefficients for the kapton ${ }^{\mathrm{TM}}$ and beryllium windows (see on Fig. 3) respectively. $N$ is the number of atoms per unit volume of the target (in $\mathrm{m}^{-3}$ ), $\mu$ (in $\mathrm{cm}^{-1}$ ) is the attenuation coefficient of the target.

At the energies provided by the accelerator, the energy loss in the ion-matter interaction process is dominated by inelastic collisions with the target electrons, see for example [30].

A simple model for the calculation of the K-shell ionization cross section is given by the Binary Encounter Approximation (BEA) [31-33]. The BEA hypothesis assumes that ionization is fully due to a classical binary interaction between the charged projectile and the target electron via an electric coulomb potential. The target nucleus and the remaining electrons are supposed to play no other role than just providing the initial momentum distribution and the binding energy $I_{k}$ of the ejected electron. In this context, Gryzinski suggested a formula for the K-shell ionization cross-section given by Eq. (8) [34]:

$\begin{aligned} \sigma_{i} & =\sigma_{0} \frac{Z_{p}^{* 2}}{I_{k}^{2}} G(V) \\ & \text { with } \sigma_{0}=\pi e^{4}=6.56 \times 10^{-14} \mathrm{~cm}^{2} \mathrm{eV}^{2}\end{aligned}$

The scaling law $G(V)$ is a function of a dimensionless value $V=\frac{v_{i}}{v_{e}}$, the ratio between the velocity of the ion and the orbital velocity of the electron. It allows calculating the ionization cross section for charged projectiles of any energy. The electronic velocity can be calculated with the assumption that the kinetic energy is equal to the binding energy of the electron in the orbit k. For $V>0.2$ the $G$ function takes the form of Eq. (9):

$G(x)=f\left[\frac{x^{2}}{1+x^{2}}+\frac{2}{3}(1+u) \ln (2.7+x)\right](1-u)\left(1-u^{1+x^{2}}\right) ; x>0.2$

With $u=(4 x(1+x))^{-1}$ and $f=\frac{1}{x^{2}}\left(\frac{x^{2}}{1+x^{2}}\right)^{3 / 2}$

$\mathrm{G}$ reaches a maximum when $x=1$, i.e. when the ion and electron velocities are similar. At lower velocities, $x<0.2$, the influence of the average field of the targets atom cannot be neglected anymore, and Eq. (8) does not fit the data [35].
The effective charge $Z_{p}^{*}$ takes into account the interplay of the projectile ionization and capture processes. It must be considered, especially at low velocities, and can be described by the empirical relation [36]:

$Z_{p}^{*}=Z_{p}\left[1-\exp \left(-125 \beta Z_{p}^{-2 / 3}\right)\right]$

where $Z_{p}$ is the particle charge and $\beta=v / c$ is the relativistic velocity factor.

The success of the method lies in its simplicity of implementation (simple calculations), in its wide generality and the fact that it gives, at least at high velocities, the same results as other models like Plane Wave Born Approximation (PWBA) or perturbed stationary state theory with energy loss, Coulomb correction and relativistic effects (ECPSSR).

Fig. 5 shows the differences between the calculated constant and the CR39 measured during the last 8 years, for various beams and energies. It is remarkable that despite the many approximations made, this simple model nevertheless correctly estimates the $\mathrm{X}$ production rate to less than $15 \%$ errors on average.

\subsubsection{Dose distribution}

As mentioned above, part of the dose distribution uncertainty stems directly from the statistical dose deposition process itself. Although the flux monitoring by X-rays does not allow to obtain geometric information on the homogeneity of the projectile distribution, it is nevertheless possible to analyze "a posteriori" the CR39 films used for the dosimetry, in a restricted range of fluence.

In localized areas of the film, taking into account a collection of small surfaces of the order of few $\mu \mathrm{m}^{2}$, an excellent agreement with a Poisson distribution is observed, as illustrated in Fig. 6.

On the basis of the results shown in Fig. 6, assuming a Poisson distribution, it is then possible to evaluate the probability that a cell's nucleus is effectively hit by an ion, or not hit at all -which is even more interesting in the statistical process of the experiment, as the bias induced by a non irradiated cell is bigger. These calculations are summarized in Table 2 for different nucleus diameters. It can be observed that in standard conditions of fluence at $5.10^{7}$ ions $/ \mathrm{cm}^{2}$ (of the order of 1 to 2 Gy for LET typical of high energy $C$ beams), one can consider with a quasi certainty that all cells are affected, whatever the supposed size of the nuclei.

It is also interesting to observe that this local impact distribution is fully confirmed at larger scale over the whole surface of the CR39 film. As shown in fig. 7 for a ${ }^{13} \mathrm{C}$ beam, a mono-modality and normal distribution are very well fitted to the data, their parameters being consistent with the local Poisson distribution.

We can also seek to extract a possible deterministic behavior overlaid on the supposed random distribution. To this purpose, a set of longitudinal cross-sections of CR39 films has been made, with a picture taken in steps of $0.5 \mathrm{~mm}$. We thus obtain a random signal over the entire length of the CR39 film.

The results of auto correlation and its Fourier transform, the power spectral density can then be compared to a Gaussian white noise equivalent (GWNE), generated by the Scilab software [37], of the same energy as the signal. As presented in Fig. 8, with a ${ }^{13} \mathrm{C}$

Table 1

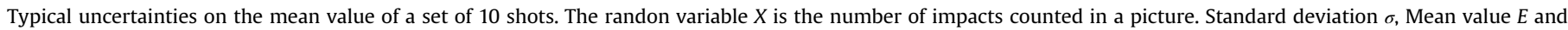
confidence interval C.I

\begin{tabular}{|c|c|c|c|c|c|c|c|c|}
\hline \multirow[t]{2}{*}{ r.v. $X$} & \multicolumn{3}{|c|}{ sample: Average of 10 shots } & \multicolumn{5}{|c|}{ fluence: $3 \cdot 10^{6}$ ions $/ \mathrm{cm}^{2}$} \\
\hline & $\sigma(X)_{\text {sample }}$ & $E(X)_{\text {sample }}$ & C.I. $(69 \%)$ & C.I. $(95 \%)$ & C.I. $(99 \%)$ & $\Delta(X) / X(2 \sigma)$ & $\Delta(X) / X(4 \sigma)$ & $\Delta(X) / X(6 \sigma)$ \\
\hline${ }^{36} \mathrm{Ar}(95 \mathrm{~A} . \mathrm{MeV})$ & 7.39 & 114.6 & 9.66 & 12.69 & 5.91 & 0.052 & 0.084 & 0.111 \\
\hline${ }^{58} \mathrm{Ni}(75 \mathrm{~A} . \mathrm{MeV})$ & 7.68 & 131.75 & 10.04 & 13.18 & 6.14 & 0.047 & 0.076 & 0.100 \\
\hline${ }^{13} \mathrm{C}(75 \mathrm{~A} . \mathrm{MeV})$ & 8.11 & 132.76 & 10.6 & 13.92 & 6.49 & 0.049 & 0.080 & 0.105 \\
\hline
\end{tabular}




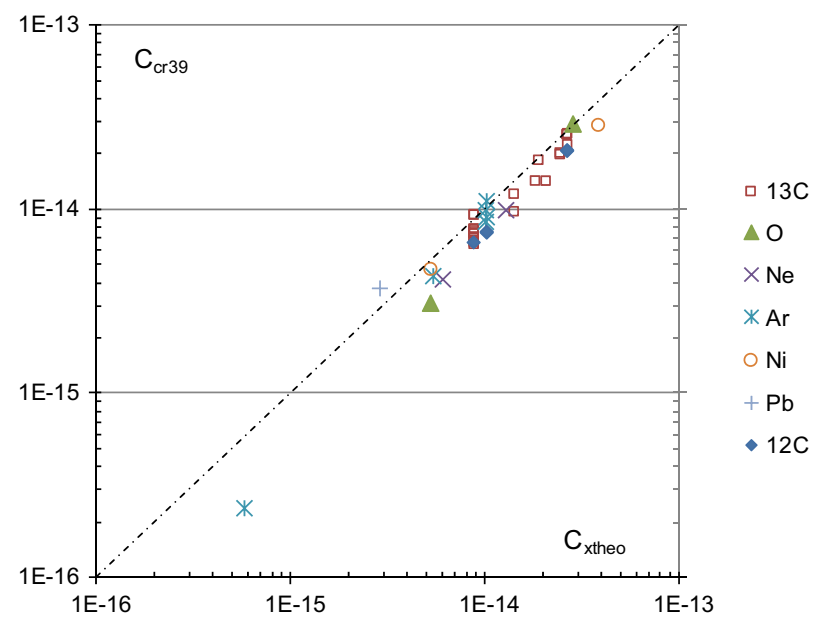

Fig. 5. CR39 calibration constant as function of theoretical constant.

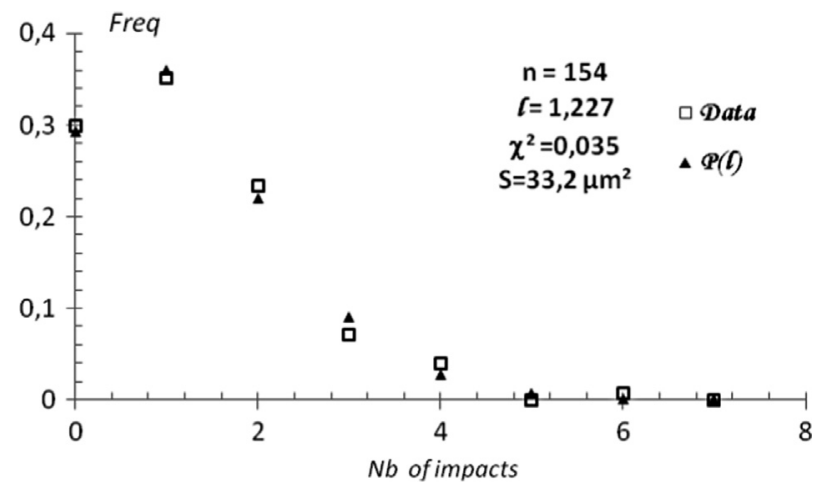

Fig. 6. Local distribution for a representative set of 154 samples of $33.2 \mu \mathrm{m}^{2}$. Comparison to the corresponding Poisson distribution. Beam: ${ }^{13} \mathrm{C}$ at $75 \mathrm{MeV} / \mathrm{A}$, fluence: $310^{6} \mathrm{ions} / \mathrm{cm}^{2}$.

Table 2

Impact probability $P(N)$ for different nuclei sizes (dim) and fluences. $\varepsilon<10^{-15}$ mean $N$ is the mean value of a Poisson distribution.

\begin{tabular}{lcclll}
\hline Fluence (ions $\left./ \mathbf{c m}^{2}\right)$ & Dim $(\boldsymbol{\mu m})$ & Mean $\boldsymbol{N}$ & $\boldsymbol{P}(\boldsymbol{N}=\mathbf{0})$ & $\boldsymbol{P}(\boldsymbol{N}=\mathbf{1})$ & $\boldsymbol{P}(\boldsymbol{N}>\mathbf{1})$ \\
\hline \multirow{2}{*}{$10^{6}$} & 5 & 0.25 & 0.779 & 0.195 & 0.026 \\
& 10 & 1 & 0.368 & 0.368 & 0.264 \\
& 15 & 2.25 & 0.105 & 0.237 & 0.657 \\
& 20 & 4 & 0.018 & 0.073 & 0.908 \\
$3.10^{6}$ & 5 & 0.75 & 0.472 & 0.354 & 0.173 \\
& 10 & 3 & 0.05 & 0.149 & 0.801 \\
& 15 & 6.75 & 0.001 & 0.008 & 0.991 \\
$10^{7}$ & 20 & 12 & $6.1410^{-6}$ & $7.3710^{-5}$ & 0.99992 \\
& 5 & 2.5 & 0.082 & 0.205 & 0.713 \\
& 10 & 10 & $4.5410^{-5}$ & $4.5410^{-4}$ & $1-\varepsilon$ \\
& 15 & 22.5 & $1.6910^{-10}$ & $3.8010^{-9}$ & $1-\varepsilon$ \\
$5.10^{7}$ & 20 & 40 & $<10^{-15}$ & $<10^{-15}$ & $1-\varepsilon$ \\
& 5 & 12.5 & $3.7610^{-6}$ & $4.6510^{-5}$ & 0.9999 \\
& 10 & 50 & $<10^{-15}$ & $<10^{-15}$ & $1-\varepsilon$ \\
& 15 & 112.5 & $<10^{-15}$ & $<10^{-15}$ & $1-\varepsilon$ \\
& 20 & 200 & $<10^{-15}$ & $<10^{-15}$ & $1-\varepsilon$ \\
\hline
\end{tabular}

beam, both signal and GWNE are very similar. The amplitude of the frequency peaks are of the same order of magnitude and no particular peak, signature of a deterministic signal, can be isolated in the spectrum. If there is any additional signal, it is not of sufficient energy to be extracted from our Gaussian white noise signal.

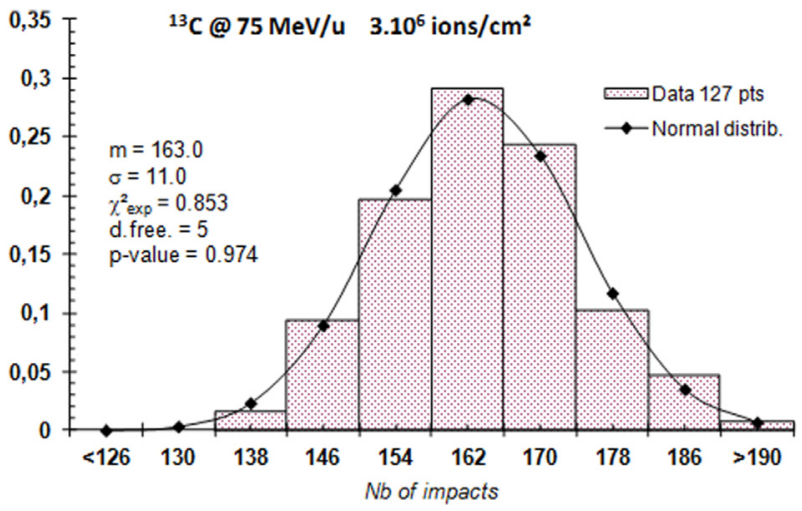

Fig. 7. Large scale distribution for a representative set of 127 samples of $60 \times 80 \mu \mathrm{m}^{2}$. Beam: ${ }^{13} \mathrm{C}$ at $75 \mathrm{MeV} / \mathrm{A}$, fluence: $310^{6}$ ions $/ \mathrm{cm}^{2}$. Comparison to the corresponding Normal distribution: Pearson's khi-square test (with a degree of freedom of 5) shows a very good adjustment at any significant level $\alpha$ up to 0.95 .
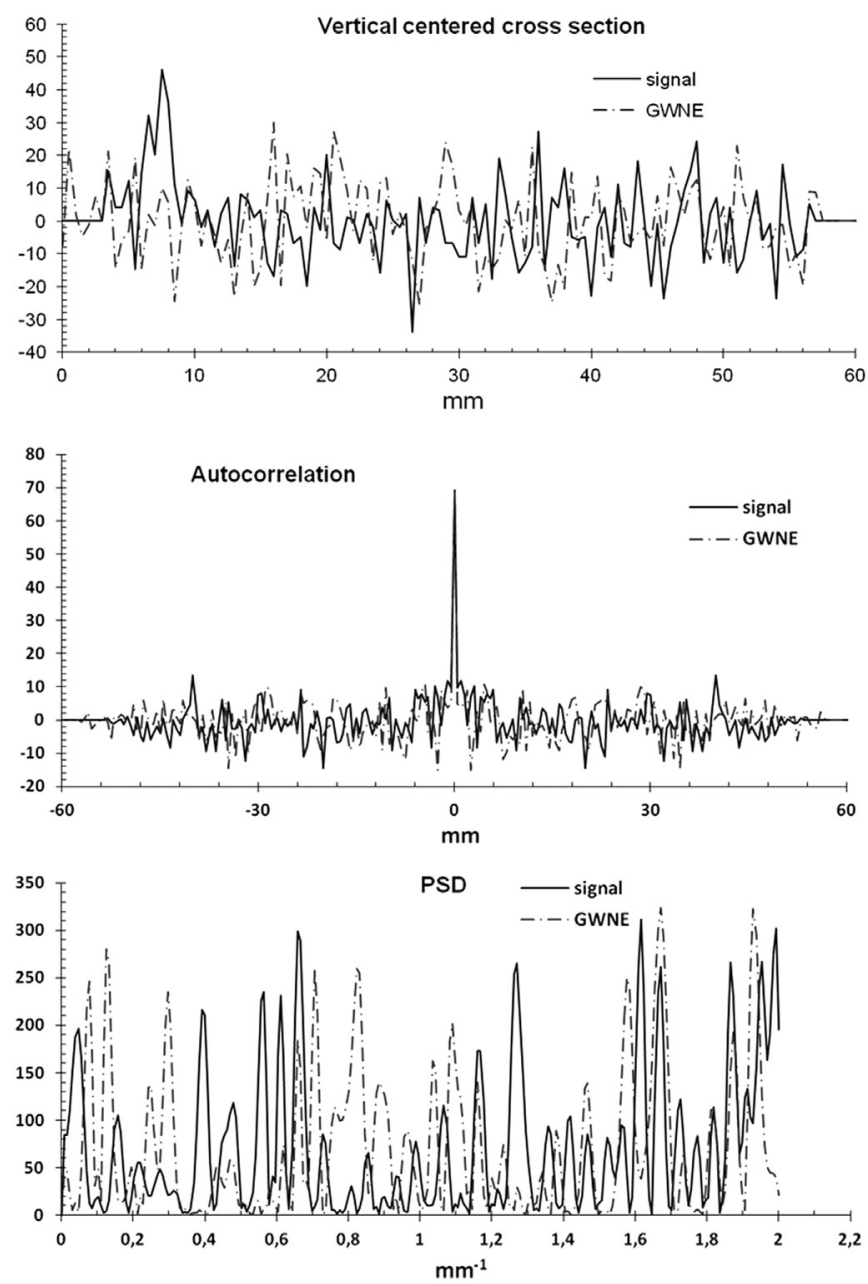

Fig. 8. Longitudinal CR39 signal and the corresponding Gaussian White Noise equivalent. $13 \mathrm{C}$ at $75 \mathrm{MeV} / \mathrm{A}$, fluence: $310^{6}$ ions $/ \mathrm{cm}^{2}$.

\section{Conclusion}

While waiting for the construction of new treatment and research centers in carbon hadron-therapy, the GANIL accelerator and the CIMAP and LARIA laboratories offer the possibility for the radio biology community to perform experiments. The facility has been presented: beams, irradiation procedures and available experimental 
Annex 1

Ion beams used on the biology platform the last 20 years, and citations.

\begin{tabular}{|c|c|c|c|c|c|c|c|c|c|}
\hline Ions & $\begin{array}{l}\text { Energy } \\
(\mathbf{M e V} / \mathbf{n})\end{array}$ & Beam & $\begin{array}{l}\text { LET }(\mathbf{k e V} / \\
\mu \mathrm{m})\end{array}$ & $\begin{array}{l}\text { Dose rate } \\
\text { (Gy/min) }\end{array}$ & Doses (Gy) & $\begin{array}{l}\text { Corresponding target fluence (water } \\
\text { equivalent) }\left(1^{6} \text { ions } / \mathrm{cm}^{2}\right)\end{array}$ & Models & Endpoints & Citations \\
\hline${ }^{12} \mathrm{C}$ & 95 & Native & 25.4 & $1-2$ & $0.5-8$ & 12.3-197 & $\begin{array}{l}\text { 2D human cells (primary \& } \\
\text { tumor) } \\
\text { 3D human cells } \\
\text { (primary \& tumor) }\end{array}$ & $\begin{array}{l}\text { Survival Proliferation Proteomics Oxydative stress } \\
\text { Histology }\end{array}$ & $\mathrm{n} / \mathrm{a}$ \\
\hline${ }^{12} \mathrm{C}$ & 95 & $\begin{array}{l}\text { PMMA } \\
(6.9 \mathrm{~mm})^{*}\end{array}$ & $34.23^{* *}$ & $1-2$ & $0.5-8$ & $9.13-146$ & & & \\
\hline${ }^{12} \mathrm{C}$ & 95 & $\begin{array}{l}\text { PMMA } \\
(13.9 \mathrm{~mm})^{*}\end{array}$ & $50.51^{* *}$ & $1-2$ & $1-8$ & $12.4-99$ & $\begin{array}{l}\text { 2D human cells (immortalized } \\
\text { \& tumor) }\end{array}$ & Colony Forming Efficiency Oxydative stress Viability & $\mathrm{n} / \mathrm{a}$ \\
\hline${ }^{12} \mathrm{C}$ & 95 & $\begin{array}{l}\text { PMMA } \\
(16.9 \mathrm{~mm})^{*}\end{array}$ & $77.26^{* *}$ & $1-2$ & $1-8$ & $8.09-64.7$ & & & $\mathrm{n} / \mathrm{a}$ \\
\hline${ }^{12} \mathrm{C}$ & 95 & $\begin{array}{l}\text { PMMA } \\
(17.9 \mathrm{~mm})^{*}\end{array}$ & $108.55^{* *}$ & $1-2$ & $1-8$ & $5.76-46.1$ & & & $\mathrm{n} / \mathrm{a}$ \\
\hline${ }^{12} \mathrm{C}$ & 75 & Native & 33.21 & $1-2$ & $0.5-6$ & $9.41-113$ & $\begin{array}{l}\text { 2D human cells (primary \& } \\
\text { tumor) } \\
\text { 3D human cells (primary \& } \\
\text { tumor) }\end{array}$ & $\begin{array}{l}\text { Survival Proliferation Proteomics Oxydative stress } \\
\text { Histology }\end{array}$ & [38] \\
\hline${ }^{13} \mathrm{C}$ & 75 & Native & 33.34 & $1-2$ & $0.5-20$ & $9.37-375$ & $\begin{array}{l}\text { 2D human cells (primary \& } \\
\text { tumor) } \\
\text { 2D human cells } \\
\text { (immortalized) } \\
\text { 3D human cells (primary \& } \\
\text { tumor) }\end{array}$ & $\begin{array}{l}\text { Survival Proliferation Apoptosis Proteomics Oxydative } \\
\text { stress Histology DNA repair Chromosomes breaks } \\
\text { Genomics }\end{array}$ & [38-55] \\
\hline${ }^{13} \mathrm{C}$ & 75 & $\begin{array}{l}\text { PMMA } \\
(6.9 \mathrm{~mm})\end{array}$ & 50.51 & $1-2$ & $0.5-6$ & $6.19-74.2$ & $\begin{array}{l}\text { 2D human cells (primary \& } \\
\text { tumor) } \\
\text { 3D human cells (primary \& } \\
\text { tumor) }\end{array}$ & $\begin{array}{l}\text { Survival Proliferation Proteomics Oxydative stress } \\
\text { Histology }\end{array}$ & $\mathrm{n} / \mathrm{a}$ \\
\hline${ }^{18} \mathrm{O}$ & 50 & Native & 85.1 & $1-2$ & $1-6$ & $7.34-44.1$ & $\begin{array}{l}\text { 2D human cells (immortalized } \\
\& \text { tumor) }\end{array}$ & Colony Forming Efficiency Viability & $\mathrm{n} / \mathrm{a}$ \\
\hline${ }^{20} \mathrm{Ne}$ & 95 & Native & 77.7 & $1-2$ & $1-6$ & $8.04-48.3$ & & & [49] \\
\hline${ }^{22} \mathrm{Ne}$ & 75 & Native & 95.5 & $1-2$ & $1-20$ & $6.54-131$ & $\begin{array}{l}\text { 2D human cells (primary \& } \\
\text { tumor) } \\
\text { 2D human cells } \\
\text { (immortalized) } \\
\text { 3D human cells (primary \& } \\
\text { tumor) }\end{array}$ & $\begin{array}{l}\text { Survival Proliferation Proteomics Oxydative stress } \\
\text { Histology }\end{array}$ & [39] \\
\hline${ }^{22} \mathrm{Ne}$ & 80 & Native & 91.2 & 1 & $1-20$ & $6.85-137$ & $\begin{array}{l}\text { 2D human cells } \\
\text { (immortalized) }\end{array}$ & Survival Cell cycle Histology & {$[39,52]$} \\
\hline${ }^{36} \mathrm{Ar}$ & 95 & Native & 271.5 & 1 & $1-20$ & $2.3-46$ & & & {$[39,49,56]$} \\
\hline${ }^{58} \mathrm{Ni}$ & 75 & Native & 905.9 & 1 & $1-20$ & $0.69-13.8$ & & & {$[39,52]$} \\
\hline${ }^{206} \mathrm{~Pb}$ & 29 & Native & 9674.0 & 1 & $1-20$ & $0.06-1.29$ & & & [39] \\
\hline
\end{tabular}

"France-Hadron. Data from LPC Caen.

*LET measurements courtesy of Guillaume Boissonnat, LPC Caen. 
devices and set up. The method of low flux beam monitoring based on X-ray measurements, and its calibration by track etched CR39 detectors has been described. Total typical errors and uncertainties are given to be less than $8 \%$ at $2 \sigma$. A description of the theoretical flux calculation has been given. Finally, a CR39 analysis shows that in standard irradiation conditions, the scanned beam behaves like an excellent Gaussian white noise.

\section{Annex 1}

See Table A1

\section{References}

[1] D. Schardt, T. Elsässer, D. Schulz-Ertner, Reviews of Modern Physics 82 (1) (2010) 383.

[2] R.R. Wilson, Radiology 47 (5) (1946) 487.

[3] NuPECC, Nuclear Physics in Medicine - Hadron-therapy, NuPECC Report, ESF NuPECC Report, ESF, 2013.

[4] H. Tsujii, T. Kamada, Japanese Journal of Clinical Oncology 42 (8) (2012) 670.

[5] H. Eickhoff, U. Linz, Reviews of Accelerator Science and Technology 01 (01) (2008) 143.

[6] A. Domaracka, C. Grygiel, A. Méry, S. Bouffard, A. Cassimi, Journal of Physics: Conference Series 629 (2015) 011001.

[7] C. Le Deroff, M. Cherel, A. Guertin, F. Haddad, C. Koumeir, V. Métivier, N. Michel, F. Poirier, N. Servagent, L. Schwob, N. Varmenot, Radiation Protection Dosimetry $161(1-4)(2014) 428$.

[8] M. Martišíková, B. Ackermann, S. Klemm, O. Jäkel, Nuclear Instruments and Methods in Physics Research Section A: Accelerators, Spectrometers, Detectors and Associated Equipment 591 (1) (2008) 171.

[9] V. Casanova Borca, M. Pasquino, G. Russo, P. Grosso, D. Cante, P. Sciacero G. Girelli, M.R. La Porta, S. Tofani, Journal of Applied Clinical Medical Physics 14 (2) (2013) 4111.

[10] S. Bouffard, J. Dural, F. Levesque, J.M. Ramillon, Annales de Physique (1989) 395.

[11] R. Hofstadter, Physical Review 75 (5) (1949) 796.

[12] G.F. Knoll, Radiation Detection and Measurement, John Wiley \& Sons, 2010.

[13] T. Kamada, H. Tsujii, E.A. Blakely, J. Debus, W. De Neve, M. Durante, O. Jäkel, R. Mayer, R. Orecchia, R. Pötter, S. Vatnitsky, W.T. Chu, The Lancet Oncology 16 (2) (2015) e93.

[14] P.D.J. Kiefer, Deposition of Radiation Energy, in: Biological Radiation Effects, Springer, Berlin Heidelberg, 1990, pp. 55-87.

[15] J. Ziegler, 'SRIM : http://www.srim.org', 2008. [Online]. Available: 〈http:/ www.srim.org $/\rangle$. (accessed: 17.09.15).

[16] B.G. Cartwright, E.K. Shirk, P.B. Price, Nuclear Instruments and Methods 153 (2-3) (1978) 457.

[17] R.M. Cassou, E.V. Benton, Nuclear Track Detection 2 (3) (1978) 173.

[18] I. Bailly, C. Champion, P. Massiot, P. Savarin, J.L. Poncy, S. Crespin, G. Alloy, V. Jacob, E. Petibon, Nuclear Instruments and Methods in Physics Research Section B: Beam Interactions with Materials and Atoms 187 (1) (2002) 137.

[19] R.L. Fleischer, P.B. Price, R.M. Walker, Nuclear Tracks in Solids: Principles and Applications, University of California Press, 1975.

[20] S. Kodaira, N. Yasuda, H. Kawashima, M. Kurano, S. Naka, S. Ota, Y. Ideguchi, N. Hasebe, K. Ogura, Radiation Measurements 46 (12) (2011) 1782.

[21] D. Zhou, CR-39 Plastic Nuclear Track Detectors in Physics Research, Nova Science Publishers, Hauppauge, N.Y, 2012.

[22] M. Yamamoto, N. Yasuda, M. Kurano, T. Kanai, A. Furukawa, N. Ishigure, K. Ogura, Nucl. Instrum. Methods Phys. Res. Sect. B Beam Interact. Mater. At $152(2-3)$ (1999) 349.

[23] H. Kozima, Characteristics of Solid-State Nuclear Track Detectors for Heavy Charged Particles - A Review, Proceedings of JCF13, Nagoya, Japan, 08-Dec2013.
[24] A.N. Golovchenko, J. Skvarc, R. Ilić, L. Sihver, V.P. Bamblevski, S.P. Tretyakova, D. Schardt, R.K. Tripathi, J.W. Wilson, R. Bimbot, Nuclear Instruments and Methods in Physics Research Section B: Beam Interactions with Materials and Atoms, 159, (1999) 233.

[25] S. Cecchini, T. Chiarusi, G. Giacomelli, M. Giorgini, A. Kumar, G. Mandrioli, S. Manzoor, A.R. Margiotta, E. Medinaceli, L. Patrizii, V. Popa, I.E. Qureshi, G. Sirri, M. Spurio, V. Togo, Nuclear Physics A 807 (3-4) (2008) 206.

[26] M. Giorgini, Nuclear Physics B 197 (1) (2009) 66.

[27] C.P. Karger, O. Jäkel, H. Palmans, T. Kanai, Phys. Med. Biol. 55 (21) (2010) R193.

[28] A. Fukumura, T. Hiraoka, K. Omata, M. Takeshita, K. Kawachi, T. Kanai, N. Matsufuji, H. Tomura, Y. Futami, Y. Kaizuka, G.H. Hartmann, Phys. Med. Biol. $43(12)$ (1998) 3459

[29] V.O. Kostroun, M.H. Chen, B. Crasemann, Physical Review A 3 (2) (1971) 533.

[30] P. Sigmund, Particle penetration and radiation effects general aspects and stopping of swift point charges, Springer, Berlin; New York, 2008.

[31] E. Gerjuoy, Physical Review 148 (1) (1966) 54.

[32] J.D. Garcia, Physical Review A 1 (2) (1970) 280.

[33] J.H. McGuire, P. Richard, Physical Review A 8 (3) (1973) 1374.

[34] M. Gryziński, Physical Review 138 (2A) (1965) A336.

[35] I.D. Kaganovich, E. Startsev, R.C. Davidson, New Journal of Physics 8 (11) (2006) 278.

[36] W.H. Barkas, Nuclear Research Emulsions, Academic Press, New York, 1963.

[37] scilab, 'Scilab : http://www.scilab.org/', 2013. [Online]. Available: 〈http://www. scilab.org/en $\rangle$. (accessed: 17.09.15).

[38] C.E. Hellweg, C. Baumstark-Khan, C. Schmitz, P. Lau, M.M. Meier, I. Testard, T. Berger, G. Reitz, Radiation Research 175 (4) (2011) 424.

[39] C.E. Hellweg, C. Baumstark-Khan, C. Schmitz, P. Lau, M.M. Meier, I. Testard, T. Berger, G. Reitz, International Journal of Radiation Biology 87 (9) (2011) 954.

[40] C. Laurent, A. Leduc, I. Pottier, V. Prévost, F. Sichel, J.-L. Lefaix, PLoS ONE 8 (12) (2013) e85158.

[41] M. Hanot, A. Boivin, C. Malésys, M. Beuve, A. Colliaux, N. Foray, T. Douki, D. Ardail, C. Rodriguez-Lafrasse, PLoS ONE 7 (11) (2012) e44367.

[42] M. Maalouf, G. Alphonse, A. Colliaux, M. Beuve, S. Trajkovic-Bodennec, P. Battiston-Montagne, I. Testard, O. Chapet, M. Bajard, G. Taucher-Scholz, C. Fournier, C. Rodriguez-Lafrasse, International Journal of Radiation Oncology 74 (1) (2009) 200.

[43] M. Beuve, G. Alphonse, M. Maalouf, A. Colliaux, P. Battiston-Montagne, P. Jalade, E. Balanzat, A. Demeyer, M. Bajard, C. Rodriguez-Lafrasse, International Journal of Radiation Oncology 71 (2) (2008) 635.

[44] D. Boucher, I. Testard, D. Averbeck, Radiation and Environmental Biophysics 45 (4) (2006) 267.

[45] I. Testard, B. Dutrillaux, L. Sabatier, International Journal of Radiation Biology 72 (4) (1997) 423.

[46] I. Testard, M. Ricoul, F. Hoffschir, A. Flury-Herard, B. Dutrillaux, B. Fedorenko, V. Gerasimenko, L. Sabatier, International Journal of Radiation Biology 70 (4) (1996) 403.

[47] I. Testard, L. Sabatier, Mutation Research 430 (2) (1999) 315.

[48] J.-P. Pouget, S. Frelon, J.-L. Ravanat, I. Testard, F. Odin, J. Cadet, Radiation Research 157 (5) (2002) 589.

[49] T. Douki, J.-L. Ravanat, J.-P. Pouget, I. Testard, J. Cadet, International Journal of Radiation Biology 82 (2) (2006) 119.

[50] G. Bertrand, M. Maalouf, A. Boivin, P. Battiston-Montagne, M. Beuve, A. Levy, P. Jalade, C. Fournier, D. Ardail, N. Magné, G. Alphonse, C. Rodriguez-Lafrasse, Stem Cell Reviews and Reports 10 (1) (2014) 114.

[51] A. Suetens, M. Moreels, R. Quintens, S. Chiriotti, K. Tabury, A. Michaux, V. Grégoire, S. Baatout, International Journal of Oncology 44 (4) (2014) 1056.

[52] A.A. Chishti, C.E. Hellweg, T. Berger, C. Baumstark-Khan, S. Feles, T. Kätzel, G. Reitz, Life Sciences in Space Research 4 (2015) 35

[53] A. Calipel, A. Lux, S. Guérin, J.-L. Lefaix, C. Laurent, M. Bernaudin, F. Mouriaux, Investigative Ophthalmology \& Visual Science 56 (5) (2015) 3085.

[54] A. Suetens, M. Moreels, R. Quintens, E. Soors, J. Buset, S. Chiriotti, K. Tabury, V. Gregoire, S. Baatout, Journal of Radiation Research 56 (1) (2015) 11.

[55] C. Giustranti, S. Rousset, E. Balanzat, E. Sage, Biochimie 82 (1) (2000) 79.

[56] C. Baumstark-Khan, C.E. Hellweg, A. Arenz, M.M. Meier, Radiation Research 164 (4 Pt 2) (2005) 527. 